\title{
Family history of cancer in benign brain tumor subtypes versus gliomas
}

\author{
Quinn T. Ostrom ${ }^{1}{ }^{\dagger+}$, Christopher McCulloh ${ }^{2+}$, Yanwen Chen ${ }^{3}$, Karen Devine ${ }^{3}$, Yingli Wolinsky ${ }^{3}$, \\ Perica Davitkov ${ }^{3}$, Sarah Robbins ${ }^{4}$, Rajesh Cherukuri ${ }^{3}$, Ashokkumar Patel ${ }^{3}$, Rajnish Gupta ${ }^{3}$, Mark Cohen $^{5}$, \\ Jaime Vengoechea Barrios ${ }^{6}$, Cathy Brewer ${ }^{7}$, Cathy Schilero ${ }^{7}$, Kathy Smolenski ${ }^{7}$, Mary McGraw ${ }^{7}$, \\ Barbara Denk ${ }^{7}$, Theresa Naska7, Frances Laube ${ }^{8,9,10}$, Ruth Steele ${ }^{8,9,10}$, Dale Greene ${ }^{8,9,10}$, Alison Kast| ${ }^{8,9,10,}$ \\ Susan Bell ${ }^{11}$, Dina Aziz ${ }^{11}$, E. A. Chiocca ${ }^{11}$, Christopher McPherson ${ }^{8,9,10}$, Ronald Warnick ${ }^{8,9,10}$, Gene H. Barnett ${ }^{7}$, \\ Andrew E. Sloan ${ }^{12}$ and Jill S. Barnholtz-Sloan ${ }^{3}$ \\ ${ }^{1}$ Department of Anthropology, Case Western Reserve University, Cleveland, OH, USA \\ ${ }^{2}$ Case Western Reserve University School of Medicine, Cleveland, OH, USA \\ ${ }^{3}$ Case Comprehensive Cancer Center, Case Western Reserve University School of Medicine, Cleveland, OH, USA \\ ${ }^{4}$ Frances Payne Bolton School of Nursing, Case Western Reserve University, Cleveland, OH, USA \\ ${ }^{5}$ Department of Pathology, Case Western Reserve University School of Medicine, Cleveland, OH, USA \\ ${ }^{6}$ Department of Internal Medicine and Center for Human Genetics, University Hospitals Case Medical Center, Cleveland, OH, USA \\ ${ }^{7}$ Department of Neurosurgery, Rose Ella Burkhardt Brain Tumor and Neuro-Oncology Center, Neurological and Taussig Cancer Institute, Cleveland Clinic, Cleveland, \\ $\mathrm{OH}$, USA \\ ${ }^{8}$ Brain Tumor Center at the University of Cincinnati Neuroscience Institute, Cincinnati, OH, USA \\ ${ }^{9}$ Department of Neurosurgery, University of Cincinnati College of Medicine, Cincinnati, OH, USA \\ ${ }^{10}$ Mayfield Clinic, Cincinnati, OH, USA \\ ${ }^{1}$ Department of Neurosurgery, Dardinger Neuro-Oncology Center, James Comprehensive Cancer Center, The Ohio State University Medical Center, Columbus, \\ $\mathrm{OH}$, USA \\ ${ }^{12}$ Department of Neurosurgery, Brain Tumor and Neuro-oncology Center, University Hospitals Case Medical Center, Case Western Reserve School of Medicine, \\ Cleveland, $\mathrm{OH}, \mathrm{USA}$
}

Edited by:

Yawei Zhang, Yale University, USA

Reviewed by:

Sophia S. Wang, City of Hope, USA

Jian Gu, The University of Texas MD

Anderson Cancer Center, USA

*Correspondence:

Quinn T. Ostrom, Department of Anthropology, Case Western Reserve

University, Mather Memorial Room

238, 11220 Bellflower Road,

Cleveland, OH 44106-5065, USA.

e-mail:qto@case.edu

${ }^{+}$Christopher McCulloh and Quinn

T. Ostrom are co-first authors.
Purpose: Family history is associated with gliomas, but this association has not been established for benign brain tumors. Using information from newly diagnosed primary brain tumor patients, we describe patterns of family cancer histories in patients with benign brain tumors and compare those to patients with gliomas. Methods: Newly diagnosed primary brain tumor patients were identified as part of the Ohio Brain Tumor Study. Each patient was asked to participate in a telephone interview about personal medical history, family history of cancer, and other exposures. Information was available from 33 acoustic neuroma (65\%), 78 meningioma (65\%), 49 pituitary adenoma (73.1\%), and 152 glioma patients (58.2\%). The association between family history of cancer and each subtype was compared with gliomas using unconditional logistic regression models generating odds ratios (ORs) and 95\% confidence intervals. Results: There was no significant difference in family history of cancer between patients with glioma and benign subtypes. Conclusion: The results suggest that benign brain tumor may have an association with family history of cancer. More studies are warranted to disentangle the potential genetic and/or environmental causes for these diseases.

Keywords: meningioma, acoustic neuroma, pituitary tumor, glioma, family history of cancer

\section{INTRODUCTION}

The overall incidence of benign and malignant brain tumors is 18.71 per 100,000 person years; 11.52 per 100,000 person years for benign tumors; and 7.19 per 100,000 person years for malignant tumors (CBTRUS, 2010). The most common benign brain tumor in adults is meningioma, followed by pituitary adenoma, and acoustic neuroma (also called schwannoma). A small proportion of meningiomas (6-8\%) are World Health Organization (WHO) grade II or grade III (Wrobel et al., 2005). Otherwise, all benign tumors are considered to be WHO grade I. The most common primary malignant brain tumors are gliomas, the most common of which is glioblastoma multiforme (GBM), a WHO grade IV tumor (CBTRUS, 2010).
The only established environmental risk factor for gliomas and meningiomas is ionizing radiation exposure to the head and neck; allergies have been inversely associated with glioma risk (Wrensch et al., 2002; Ohgaki and Kleihues, 2005; Barnholtz-Sloan and Kruchko, 2007; Bondy et al., 2008). Inherited syndromes such as neurofibromatosis 1 and 2, tuberous sclerosis, Li-Fraumeni syndrome, and Turcot syndrome can also increase one's and one's family members' risk for both malignant and benign brain tumors as well as for other cancers (Louis and von Deimling, 1995; Malmer et al., 2005). In addition, multiple studies have shown an increased risk of brain tumors and other cancers for family members of sporadic glioma or meningioma patients (Hemminki et al., 2001; Hill et al., 2003, 2004). 
While many studies have established an association between family history of cancer and glioma, few have assessed patterns of family history of cancer in benign brain tumor subtypes (Bondy et al., 2008; McCarthy et al., 2011). The relationship between glioma and family history of cancer has been explored by several investigators, and family history of malignancy has been established as a risk factor for gliomas (Hemminki et al., 2000, 2001, 2007; Hemminki and Li, 2004). The studies that have looked into benign brain tumor subtypes primarily focus on meningioma and/or acoustic neuroma only, and while some have shown significant associations between family history of cancer and increased odds of a brain tumor, others have shown no association (Sakas et al., 1994; Louis and von Deimling, 1995; Maxwell et al., 1998; Hemminki et al., 2000, 2001; King and Gutmann, 2000; Hill et al., 2003, 2004; Malmer et al., 2003; Bacci et al., 2010).

While studies have utilized large databases to assess family history of cancer as a potential risk factor for some benign brain tumor types, most have just examined family history of specific cancer types, such as brain tumors or other central nervous system tumors. No prior studies could be identified that examine differences in family history of cancer between benign primary brain tumors and gliomas. No previous study has established family history of cancer as a risk factor for benin brain tumors, though they have suggested associations between benign brain tumors and some specific cancer types. Because a family history of malignancy has been previously established as a risk factor for gliomas (Hemminki et al., 2000, 2001, 2007; Hemminki and Li, 2004) our study uses a group of patients with glioma as a reference group to establish whether family history of cancer may be associated with benign brain tumor types, using information from newly diagnosed primary brain tumor patients enrolled in a multi-site study within Ohio.

\section{MATERIALS AND METHODS THE OHIO BRAIN TUMOR STUDY}

The Ohio Brain Tumor Study (OBTS) is a multi-site study in Ohio that prospectively accrues newly diagnosed, untreated brain tumor patients. This network is comprised of four major academic brain tumor centers in the state of Ohio: The Brain Tumor and Neuro-Oncology Center at University Hospitals Case Medical Center (UHCMC) the clinical affiliate of the Case Western Reserve University (CWRU) School of Medicine, the Rose Ella Burkhardt Brain Tumor and Neuro-Oncology Center at the Cleveland Clinic (CC), The Dardinger Neuro-Oncology Center, Department of Neurosurgery at the James Cancer Hospital and the Ohio State University Medical Center (OSU) and the Brain Tumor Center at the University of Cincinnati (UC). All newly diagnosed primary brain tumor patients are identified at each center by research nurses, and informed consent is obtained. Patients that have been diagnosed with a familial cancer syndrome are excluded. From each the following are obtained: blood sample, snap-frozen tumor tissue within $30 \mathrm{~min}$ of resection, and/or re-cuts of formalinfixed, paraffin embedded (FFPE) tumor tissue (for histopathology review), interview/questionnaire data, medical chart review, and active yearly follow-up for clinical outcomes. All sites have their own IRB approvals and use the same standardized study protocol, procedures, and informed consent. In addition each OBTS site has a fully executed Research/Material Transfer Agreement with CWRU.

\section{QUESTIONNAIRE AND VARIABLES OF INTEREST}

Each subject is asked to take part in a telephone interview lasting 30-45 min. The interview uses a standardized questionnaire for all patients that includes questions regarding subjects' medical history, family history of cancer, medication history, tobacco use, and other environmental exposure history (potential exposures they may have been exposed to during work or hobbies). All patients are administered the same questionnaire, and all questionnaire interviews for all sites are performed by the CWRU research staff. If the patient is unable to complete the questionnaire, a proxy is allowed to complete the interview. To limit recall bias, interviews are conducted shortly after completion of surgery and neoadjuvant treatment. Clinical variables, such as type of tumor (meningioma, acoustic neuroma, pituitary, astrocytoma, oligodendroglioma, oligoastrocytoma), and WHO grade of tumor (I, II, III, IV), were abstracted from patient medical records. Family history of cancer information was not confirmed via clinical records.

The questionnaires are constructed to elicit the following variables of interest: age at diagnosis, gender, and detailed family history of cancer. Due to small sample sizes of oligodendrogliomas and oligoastrocytomas, these subtypes were grouped with astrocytomas into "gliomas" for analysis, and due to small sample sizes of atypical and anaplastic meningiomas, i.e., grade II and III, all meningiomas were analyzed together as a single group. Family history of cancer was coded as a four level variable: none, first-degree only, second-degree only, and first and second-degree. The type of relative and type of cancer that the relative had were also recorded for all relatives.

\section{STATISTICAL ANALYSIS}

Frequency and proportions were calculated for all variables of interest and categorized by tumor subtypes. Chi-square and Fisher's exact tests were used to test for differences in key variables of interest within each subtype classification. The association between family history of cancer (none, first-degree only, seconddegree only, and first and second-degree, and by specific cancer types) and each benign subtype as compared to gliomas was modeled using an unconditional logistic regression model generating odds ratios (ORs) and 95\% confidence intervals (95\% CI). Logistic regression models were compared to the Base model, which included the adjustment factors only, using a likelihood ratio test (LRT) generating a two-sided $p$-value.

\section{RESULTS}

Initially, 494 subjects that met histological criteria were consented for OBTS and follow-up interviews were completed with 312 (63.2\% overall; Table 1). The highest proportion of interviews were obtained from patients with pituitary tumors $(73.1 \%$ overall). The majority of benign brain tumor patients were female, and had an average age at diagnosis of 54 years. Interestingly, $20.5 \%$ of patients with meningiomas and $22.4 \%$ of patients with pituitary tumors were non-white as compared to $0 \%$ of acoustic neuroma patients (Fisher's exact $p$-value $=0.004$; Table 1). Eighty-six percent of meningiomas were grade I tumors. The majority of glioma 


\begin{tabular}{|c|c|c|c|c|c|c|c|c|c|c|c|c|c|c|c|}
\hline & & \multicolumn{7}{|c|}{ Benign subtypes } & \multicolumn{7}{|c|}{ Gliomas } \\
\hline & & \multicolumn{2}{|c|}{ Meningioma } & \multicolumn{2}{|c|}{$\begin{array}{l}\text { Acoustic } \\
\text { neuroma }\end{array}$} & \multicolumn{2}{|c|}{$\begin{array}{l}\text { Pituitary } \\
\text { adenoma }\end{array}$} & \multirow[t]{2}{*}{$p$-Value ${ }^{a}$} & \multicolumn{2}{|c|}{ Astrocytoma } & \multicolumn{2}{|c|}{$\begin{array}{l}\text { Oligo- } \\
\text { dendroglioma }\end{array}$} & \multicolumn{2}{|c|}{$\begin{array}{l}\text { Oligo- } \\
\text { astrocytoma }\end{array}$} & \multirow[t]{2}{*}{$p$-Value ${ }^{b}$} \\
\hline \multicolumn{2}{|l|}{ Total consented } & 120 & & 46 & & 67 & & & 223 & & 27 & & 11 & & \\
\hline \multicolumn{2}{|c|}{ Total interviewed ${ }^{c}$} & 78 & $65.0 \%$ & 33 & $71.7 \%$ & 49 & $73.1 \%$ & & 131 & $58.7 \%$ & 16 & $59.3 \%$ & 5 & $45.5 \%$ & \\
\hline \multirow[t]{2}{*}{ Interview type } & Proband & 76 & $97.44 \%$ & 32 & $96.97 \%$ & 49 & $100.0 \%$ & & 96 & $73.28 \%$ & 16 & $100.0 \%$ & 4 & $80 \%$ & \\
\hline & Proxy & 2 & $2.66 \%$ & 1 & $3.03 \%$ & 0 & $0.0 \%$ & & 35 & $26.72 \%$ & 0 & $0.0 \%$ & 1 & $20 \%$ & \\
\hline \multirow[t]{2}{*}{ Gender } & Male & 27 & $34.6 \%$ & 17 & $51.5 \%$ & 22 & $44.9 \%$ & 0.2101 & 77 & $58.8 \%$ & 12 & $75.0 \%$ & 2 & $40.0 \%$ & $0.3321^{d}$ \\
\hline & Female & 51 & $65.4 \%$ & 16 & $48.5 \%$ & 27 & $55.1 \%$ & & 54 & $41.2 \%$ & 4 & $25.0 \%$ & 3 & $60.0 \%$ & \\
\hline \multirow[t]{2}{*}{ Race } & White & 62 & $79.5 \%$ & 33 & $100 \%$ & 38 & $77.6 \%$ & $0.0039^{d}$ & 120 & $91.6 \%$ & 15 & $93.8 \%$ & 5 & $100.0 \%$ & $1.0000^{d}$ \\
\hline & Black/other & 16 & $20.5 \%$ & 0 & $0 \%$ & 11 & $22.4 \%$ & & 11 & $8.4 \%$ & 1 & $6.3 \%$ & 0 & $0.0 \%$ & \\
\hline \multicolumn{2}{|c|}{$\begin{array}{l}\text { Mean age at diagnosis } \\
\text { (minimum, maximum) }\end{array}$} & \multicolumn{2}{|c|}{$55(22-85)$} & \multicolumn{2}{|c|}{$53(31-75)$} & \multicolumn{2}{|c|}{$53(29-75)$} & & \multicolumn{2}{|c|}{$57(20-92)$} & \multicolumn{2}{|c|}{$43(28-66)$} & \multicolumn{2}{|c|}{47 (19-65) } & \\
\hline \multirow[t]{5}{*}{ Histology } & Grade I & 67 & $85.9 \%$ & 33 & $100.0 \%$ & 0 & $0.0 \%$ & & 1 & $0.8 \%$ & 0 & $0.0 \%$ & 0 & $0.0 \%$ & \\
\hline & Grade II & 10 & $12.8 \%$ & 0 & $0.0 \%$ & 0 & $0.0 \%$ & & 10 & $7.6 \%$ & 9 & $56.3 \%$ & 3 & $60.0 \%$ & \\
\hline & Grade III & 1 & $1.3 \%$ & 0 & $0.0 \%$ & 0 & $0.0 \%$ & & 13 & $9.9 \%$ & 6 & $37.5 \%$ & 2 & $40.0 \%$ & \\
\hline & Grade IV & 0 & $0.0 \%$ & 0 & $0.0 \%$ & 0 & $0.0 \%$ & & 105 & $80.2 \%$ & 0 & $0.0 \%$ & 0 & $0.0 \%$ & \\
\hline & No grade & 0 & $0.0 \%$ & 0 & $0.0 \%$ & 49 & $100.0 \%$ & & 0 & $0.0 \%$ & 0 & $0.0 \%$ & 0 & $0.0 \%$ & \\
\hline
\end{tabular}

${ }^{a}$ Measures significance of difference between the benign brain tumor subtypes for distribution of this variable.

${ }^{b}$ Measures significance of difference between the glial brain tumor subtypes for distribution of this variable.

'Some participants declined to provide family history. This population is used for calculating the percentages in the rest of the table.

${ }^{d}$ Fisher's exact test.

patients were male, white, and had an average age at diagnosis of 55.2 years (Table 1). The majority of gliomas were glioblastomas (Table 1).

Of the 312 patients interviewed, $74.68 \%$ reported a first or second-degree family history of cancer (Table 2). Those with a pituitary adenoma reported the highest proportion of family history of cancer $(81.63 \%)$. In comparison, this proportion was $75.64 \%$ for the meningiomas, $75.76 \%$ for the acoustic neuromas, and $71.71 \%$ for the gliomas (Table 2). Overall, 56\% of patients reported at least one first-degree relative with cancer. Proportions with first-degree history of cancer were $58.98 \%$ for meningioma patients, $45.45 \%$ for acoustic neuroma patients, $51.02 \%$ for pituitary adenoma patients, and $57.89 \%$ for glioma patients. Notably, there are high proportions of colorectal cancers and nervous system cancers across all subtypes. Overall, the most common cancer types in this population's family members were lung, colorectal, breast, prostate, and brain.

Comparisons between each of the benign brain tumor types and gliomas showed that for patients with benign subtypes, there is no difference in the odds of having a first-degree or second-degree relative with cancer. Patients with meningioma had decreased odds of having a first-degree relative with breast cancer compared to glioma patients after adjustment for age at diagnosis, gender, family size, and race $[\mathrm{OR}=0.225,95 \%$ CI $(0.059-0.857)$, LRT $p$-value $=0.082$; Table 3] .

\section{DISCUSSION}

The population accrued by the OBTS and the subpopulation included in this analysis are demographically similar to the broader US population of brain tumor patients, with our subpopulation being $50.32 \%$ male and $87.5 \%$ white (Table 1). The Central Brain Tumor Registry of the US (CBTRUS) was $43.11 \%$ male and $84.81 \%$ white (CBTRUS, 2010). Of note are the relatively high proportions of non-white meningioma and pituitary patients in the OBTS population. The CBTRUS data also show a higher incidence of meningiomas and pituitary tumors and a lower incidence of gliomas in blacks as we observed in our OBTS study population. US population-based data show a female dominance for meningiomas, as we had in the OBTS study (CBTRUS, 2010). The similarities between the OBTS population and that reported in CBTRUS suggest that brain tumor patient population shares many demographic characteristics with the United States population with brain tumor at large.

The overall proportions of family history of cancer in this population are high when compared to previous studies of the general population (Ramsey et al., 2006) and the proportion of first-degree family history of cancer in this population is comparable to that found in a hospital-based study of malignant brain tumor patient populations (Scheurer et al., 2007). Previous registry and case control studies have found an elevated risk for specific cancers particularly nervous system cancers (Hemminki et al., 2000, 2001; Malmer et al., 2003), or family history of cancer in first-degree relatives of persons with meningioma (Hill et al., 2004). A family study conducted by Sakas et al. (1994) found no significant difference in family history of cancer between persons with benign or malignant brain neoplasms and healthy controls. Our population reported relatively high rates of nervous system cancers in first and seconddegree relatives, compared to previous studies that have suggested elevated standard incidence ratios for nervous systems in firstdegree family members of persons with meningioma (Hemminki 
Table 2 | Overall and site-specific family history of cancer by brain tumor histologic type.

\begin{tabular}{|c|c|c|c|c|c|c|c|c|c|}
\hline \multirow{2}{*}{$\begin{array}{l}\text { Cancer site } \\
\text { Overall }\end{array}$} & \multirow{2}{*}{$\begin{array}{l}\text { Degree of relative } \\
\text { with cancer } \\
\text { None }\end{array}$} & \multicolumn{2}{|c|}{$\begin{array}{l}\text { Meningioma } \\
(n=78)\end{array}$} & \multicolumn{2}{|c|}{$\begin{array}{l}\text { Acoustic neuroma } \\
(n=33)\end{array}$} & \multicolumn{2}{|c|}{$\begin{array}{l}\text { Pituitary adenoma } \\
(n=49)\end{array}$} & \multicolumn{2}{|c|}{$\begin{array}{l}\text { All gliomas } \\
(n=152)\end{array}$} \\
\hline & & 19 & $24.36 \%$ & 8 & $24.24 \%$ & 9 & $18.37 \%$ & 43 & $28.29 \%$ \\
\hline & $2^{\circ}$ & 13 & $16.67 \%$ & 10 & $30.30 \%$ & 15 & $30.61 \%$ & 21 & $13.82 \%$ \\
\hline & $1^{\circ}$ and $2^{\circ}$ & 24 & $30.77 \%$ & 8 & $24.24 \%$ & 12 & $24.49 \%$ & 30 & $19.74 \%$ \\
\hline \multirow[t]{3}{*}{ Breast } & None & 67 & $85.90 \%$ & 26 & $78.79 \%$ & 34 & $69.39 \%$ & 119 & $78.29 \%$ \\
\hline & $2^{\circ}$ & 6 & $7.69 \%$ & 4 & $12.12 \%$ & 8 & $16.33 \%$ & 11 & $7.24 \%$ \\
\hline & $1^{\circ}$ and $2^{\circ}$ & 2 & $2.56 \%$ & 0 & $0.00 \%$ & 1 & $2.04 \%$ & 4 & $2.63 \%$ \\
\hline \multirow[t]{3}{*}{ Colon } & None & 65 & $83.33 \%$ & 29 & $87.88 \%$ & 40 & $81.63 \%$ & 143 & $94.08 \%$ \\
\hline & $1^{\circ}$ & 8 & $10.26 \%$ & 1 & $3.03 \%$ & 2 & $4.08 \%$ & 6 & $3.95 \%$ \\
\hline & $2^{\circ}$ & 4 & $5.13 \%$ & 3 & $9.09 \%$ & 6 & $12.24 \%$ & 3 & $1.97 \%$ \\
\hline & $1^{\circ}$ and $2^{\circ}$ & 0 & $0.00 \%$ & 0 & $0.00 \%$ & 1 & $2.04 \%$ & 0 & $0.00 \%$ \\
\hline \multirow[t]{4}{*}{ Lung } & None & 59 & $75.64 \%$ & 25 & $75.76 \%$ & 36 & $73.47 \%$ & 116 & $76.32 \%$ \\
\hline & $1^{\circ}$ & 9 & $11.54 \%$ & 2 & $6.06 \%$ & 3 & $6.12 \%$ & 24 & $15.79 \%$ \\
\hline & $2^{\circ}$ & 9 & $11.54 \%$ & 5 & $15.15 \%$ & 10 & $20.41 \%$ & 12 & $7.89 \%$ \\
\hline & $1^{\circ}$ and $2^{\circ}$ & 1 & $1.28 \%$ & 1 & $3.03 \%$ & 0 & $0.00 \%$ & 0 & $0.00 \%$ \\
\hline \multirow[t]{4}{*}{ Brain } & None & 66 & $84.62 \%$ & 29 & $87.88 \%$ & 40 & $81.63 \%$ & 132 & $86.84 \%$ \\
\hline & $1^{\circ}$ & 6 & $7.69 \%$ & 0 & $0.00 \%$ & 2 & $4.08 \%$ & 13 & $8.55 \%$ \\
\hline & $2^{\circ}$ & 6 & $7.69 \%$ & 3 & $9.09 \%$ & 7 & $14.29 \%$ & 7 & $4.61 \%$ \\
\hline & $1^{\circ}$ and $2^{\circ}$ & 0 & $0.00 \%$ & 1 & $3.03 \%$ & 0 & $0.00 \%$ & 0 & $0.00 \%$ \\
\hline
\end{tabular}

and Li, 2004). Previous studies have not compared benign brain tumor populations to brain tumor populations where family history of cancer is a established risk factor. Previous studies have largely not examined overall family history of cancer, but rather have focused on specific cancer types.

Both case control and registry-based studies have suggested an association between breast cancer (or a family history of breast cancer) and either meningiomas or pituitary adenomas (Hill et al., 2004; Hemminki et al., 2007). We found decreased odds of having a first-degree relative with breast cancer for meningioma patients, as compared to all glioma patients. Our data do not show that either pituitary adenoma or acoustic neuroma has a statistically greater or lesser likelihood of having a relative with breast cancer. Hemminki et al. (2007) showed an association between patients with pituitary adenoma and siblings with colorectal and breast cancer, as well as other tumor types, in a study based on validated registry data.

The OBTS accrues newly diagnosed primary benign and malignant brain tumor patients from four large tertiary referral centers in Ohio. Recruiting from tertiary care centers allows the OBTS to recruit a higher proportion of higher grade and malignant tumors, while recruiting less low grade and non-malignant tumors. A standardized protocol for screening, patient accrual and data collection is used at all participating sites. Telephone interviews and medical chart reviews are done centrally by staff from CWRU, using a regular study staff that has all completed the same standardized training to minimize bias. Though the sample size of this analysis is considerable considering the rarity of brain tumors, the small sample size results in some instability of the data produced by the analysis. Previous studies that have examined the relationship between family history and brain tumors have been based on populations between 3239 and 11,875 in registry-based studies (Malmer et al., 2003; Hemminki et al., 2007), 96 in case control studies (Hill et al., 2004), and 142 in family-based studies (Sakas et al., 1994). Previous studies examining the relationship between family history of cancer and glioma have been based on populations between 462 and 489 in case control studies (Wrensch et al., 1997; Hill et al., 2003), 20358 in registry-based studies (Malmer et al., 2003), and between 639 and 1476 in family-based studies (de Andrade et al., 2001; Scheurer et al., 2007). The population used in this analysis is on the lower end of this spectrum, but is comparable to previous studies. Accrual of additional patients over time will improve the power to detect associations. A similar analysis with registry data that contains clinically validated family history data would also build upon the correlation suggested by this analysis.

Using patients with gliomas as a comparison group presents significant limitations for the results of this analysis. While an analysis using a control group of persons without brain tumor would produce more generalizable data about risk of benign brain tumor based on family history of cancer, using a reference group known to have an increased risk of family history of cancer also provides an informative comparison. Though this does not establish family history of a cancer as a risk factor for benign brain tumors, it does suggest that there may be some association between the two 


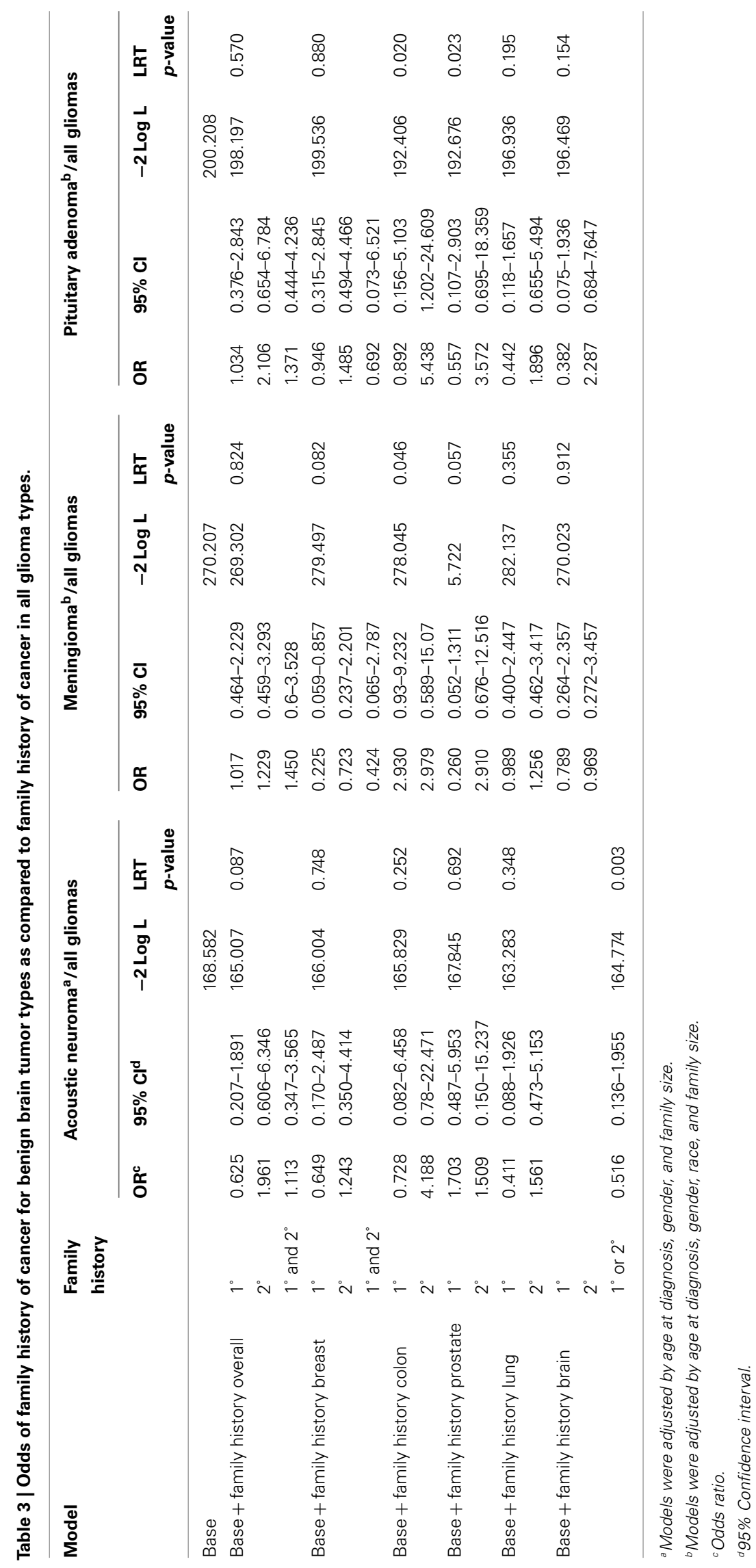




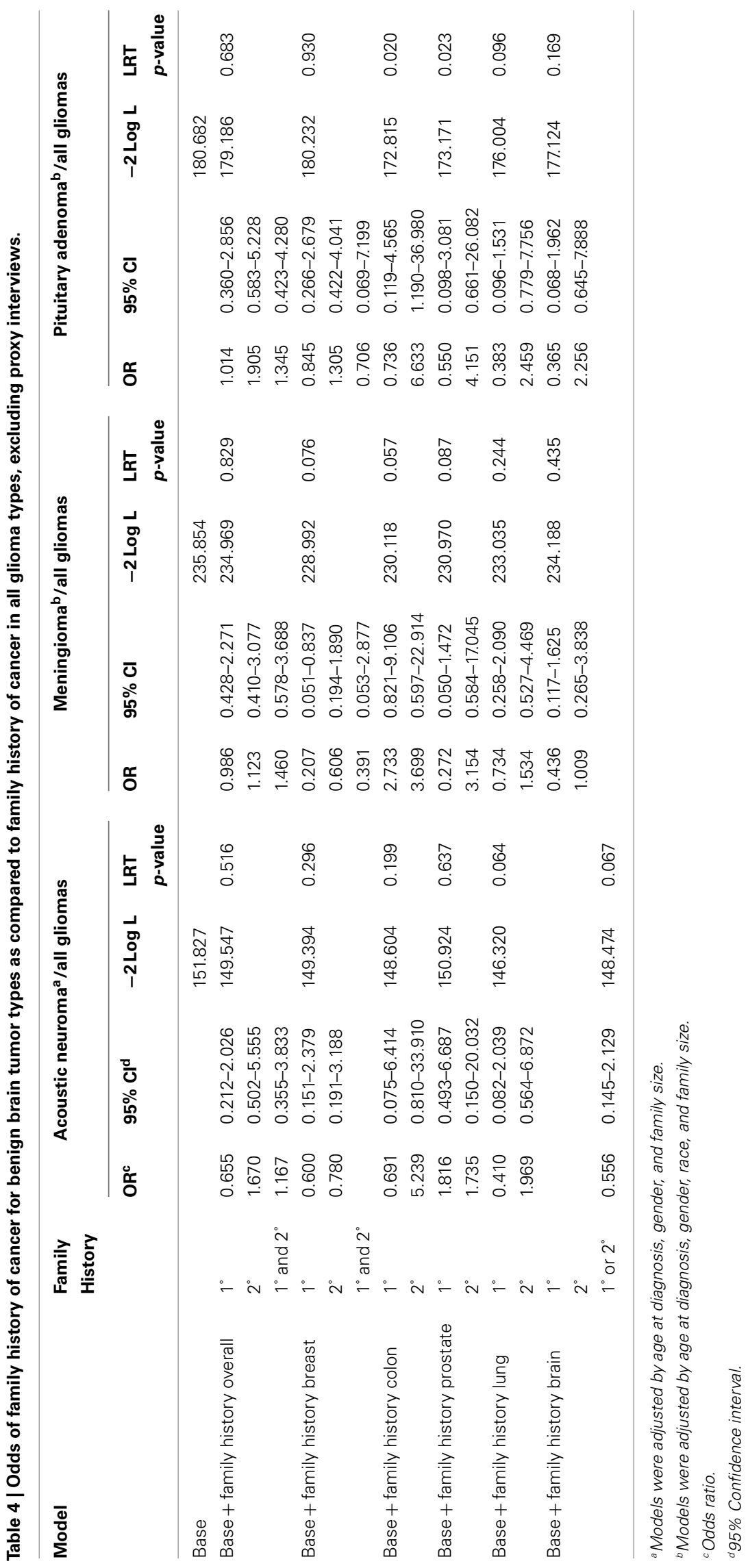


when compared to persons with glioma that are known to have an increased risk of family history of cancer. Future comparison of this benign brain tumor population with healthy controls would provide more information about family history of cancer as a risk factor for benign brain tumors. Additionally, there may be other potential factors that may be related to increased family history of cancer were not included in this analysis.

All of the family history data used in the current analysis were collected from patient self-report via telephone interview with a standardized questionnaire, where only $3 \%$ of the interviewed population chose not to answer questions about their family history of cancer. Though family history information was not validated using medical records, previous studies have concluded that subjects are able to accurately report the cancer history of family members without observable bias, but that cancer site-specific recall may be less accurate than recall of whether a cancer history exists (Kerber and Slattery, 1997; Airewele et al., 1998). Even with cancer site-specific recall difficulties, researchers have found that first-degree relative cancer history is reported at $83 \%$ accuracy, and second-degree relative cancer history is reported at $67 \%$ (Love et al., 1985). Mai et al. (2011) found that site-specific recall may generally be less accurate than this, finding positive predictive values of $40 \%$ for lung cancer, $53.5 \%$ for colorectal cancer, $61.3 \%$ for breast cancer, and $53.4 \%$ for prostate cancer, with reporting on first-degree relatives being significantly more accurate than second-degree relatives. Thus the information about whether a family cancer exists collected via the questionnaire is assumed to be largely accurate, although the site-specific information may be less dependable. The study design of the OBTS consorsium does not currently allow for validation of family cancer history data via family medical records, though this would improve the validity generalizability of this analysis. This difference between odds for first-degree versus second-degree relatives may be a result of the decreased reliability of patient self-report of second-degree relative cancer history. In addition, the site-specific ORs may have occurred by chance due to the lack of reliability of site-specific self-report of family history of cancer.

Some patients in the OBTS study died before the interview was initiated or were otherwise lost to follow-up, and others declined to participate in the interview after initial consent. Participation was particularly low among patients with astrocytomas, oligodendrogliomas, and oligoastrocytomas $(58.75,59.3$, and $45.5 \%$ interview participation, respectively). We surmise that this might reflect the additional stresses these patients were subjected to due to the need for adjuvant therapies that was uncommon in the other groups, though this was not quantified. This may also represent a survival bias, as persons that died shortly after or during surgery or treatment were excluded from this analysis. Median survival for persons with glioma who were not interviewed versus those who were interviewed was significantly different, with median survival

Table 5 | Characteristics of interviewed and non-interviewed patients.

\begin{tabular}{|c|c|c|c|c|c|c|}
\hline & & \multicolumn{2}{|c|}{ Interviewed } & \multicolumn{2}{|c|}{ Not interviewed } & \multirow{2}{*}{$\begin{array}{c}\boldsymbol{p} \text {-Value } \\
0.8674\end{array}$} \\
\hline \multicolumn{2}{|l|}{ Male } & 157 & $50.32 \%$ & 93 & $51.10 \%$ & \\
\hline \multicolumn{2}{|l|}{ White } & 273 & $87.50 \%$ & 156 & $85.71 \%$ & 0.5711 \\
\hline \multicolumn{2}{|c|}{ Median age (minimum, maximum) } & \multicolumn{2}{|c|}{$55(19,92)$} & \multicolumn{2}{|c|}{$56(21,86)$} & 0.5111 \\
\hline Mean survival (95\% Cl; days) & All gliomas & \multicolumn{2}{|c|}{190 (152-307) } & \multicolumn{2}{|c|}{523 (406-689) } & $<0.001$ \\
\hline \multirow[t]{16}{*}{ Histologic type } & Acoustic neuroma & 33 & $100 \%$ & 13 & $100 \%$ & \\
\hline & Meningioma & & & & & \\
\hline & Grade / & 67 & $85.90 \%$ & 25 & $64.10 \%$ & 0.0067 \\
\hline & Grade II-III & 11 & $14.10 \%$ & 14 & $35.90 \%$ & \\
\hline & Pituitary adenoma & 49 & $100 \%$ & 18 & $100 \%$ & \\
\hline & Astrocytoma & & & & & $0.6345^{a}$ \\
\hline & Grade I & 1 & $0.78 \%$ & 2 & $2.22 \%$ & \\
\hline & Grade /I & 10 & $7.75 \%$ & 10 & $11.11 \%$ & \\
\hline & Grade III & 13 & $10.08 \%$ & 7 & $7.78 \%$ & \\
\hline & Grade IV & 105 & $81.40 \%$ & 71 & $78.89 \%$ & \\
\hline & Oligoastrocytoma & & & & & $1.0000^{a}$ \\
\hline & Grade // & 3 & $60.00 \%$ & 4 & $66.67 \%$ & \\
\hline & Grade III & 2 & $40.00 \%$ & 2 & $33.33 \%$ & \\
\hline & Oligodendroglioma & & & & & $0.3945^{a}$ \\
\hline & Grade // & 9 & $60.00 \%$ & 9 & $81.82 \%$ & \\
\hline & Grade III & 6 & $40.00 \%$ & 2 & $18.18 \%$ & \\
\hline \multirow[t]{5}{*}{ Grade } & No grade & 49 & $15.86 \%$ & 18 & $10.17 \%$ & 0.0047 \\
\hline & Grade I & 101 & $32.69 \%$ & 40 & $22.60 \%$ & \\
\hline & Grade II & 32 & $10.36 \%$ & 35 & $19.77 \%$ & \\
\hline & Grade III & 22 & $7.12 \%$ & 13 & $7.34 \%$ & \\
\hline & Grade IV & 105 & $33.98 \%$ & 71 & $40.11 \%$ & \\
\hline
\end{tabular}

${ }^{a}$ Fisher exact test. 
of 190 days (95\% CI $152-307)$ and 523 days (95\% CI 406-689) respectively $(p<0.001)$. Overall, our response rate was very good when compared to other survey or questionnaire-based studies. A particular strength is the structured interview, which may have allowed us to better elicit family history data.

When a patient was unable to complete the telephone interview, a proxy was allowed to complete the interview on behalf of that patient. Rates of proxy interview were relatively low in the benign tumor types $(3.03 \%$ for acoustic neuromas, $2.66 \%$ for meningiomas, and $0 \%$ for pituitary tumors; Table 1 ). In the glioma types, rates were higher, particularly in the astrocytomas and oligoastrocytomas (rates of proxy interview were 26.72 and $20 \%$ respectively; Table 1). When these proxy interviews were excluded from the analysis, the effects detected in the overall comparison remained (Table 4).

The population that consented to the study but did not participate in the interview had no statistically significant difference in gender, race, or age, with the population that completed the interview (Table 5). However, among meningioma patients, the uninterviewed population had a significantly increased proportion of higher grade tumors (14.10\% grade II or III in the interviewed population and $35.90 \%$ grade II or III in the un-interviewed population, $p=0.0067$; Table 2). There was no significant difference in the proportion of grades in the astrocytoma ( $81.4 \%$ grade IV in the interviewed population and $78.9 \%$ grade IV in the un-interviewed population), oligodendroglioma ( $40 \%$ grade III in the interviewed population and $33.39 \%$ grade III in the un-interviewed population), or oligoastrocytoma (40\% grade III in the interviewed population and $18.9 \%$ grade III in the un-interviewed population) patients (Table 5). As this study involves patients who may be very ill and have significant neurocognitive problems, an overall interview rate of $63.16 \%$ is considered high. Because of the small sample size of atypical meningiomas, all meningiomas were grouped together for analysis. In addition, all gliomas were grouped together for analysis regardless of subtype because of the small number of non-astrocytic gliomas. Therefore, our meningioma results could be biased toward grade I meningiomas and our glioma results could be biased toward glioblastomas. Glioblastoma only comparisons still showed significantly increased odds of patients with pituitary adenomas having a second-degree relative with cancer.

In conclusion, the odds of having a first or second-degree relative with cancer are not significantly different between patients with benign tumors and patients with gliomas. As previous research has established an association between family history of cancer and gliomas, this suggests that it may also be associated

\section{REFERENCES}

Airewele, G., Adatto, P., Cunningham, Sharp, M., Sigurdson, A., and Bondy, M. (1998). Family history of cancer in patients with glioma: a validation study of accuracy. J. Natl. Cancer Inst. 90, 543-544.

Bacci, C., Sestini, R., Provenzano, A., Paganini, I., Mancini, I., Porfirio, B., Vivarelli, R., Genuardi, M., and Papi, J., Mastromarino, C., Spencer, C., with benign brain tumors. Previous research has not established family history of cancer as a risk factor for benign brain tumors, and have produced some conflicting results. Our study and others suggest that more family studies of brain tumor subtypes are warranted to disentangle the potential genetic and/or environmental causes for familial occurrence of these neoplasms.

\section{ACKNOWLEDGMENTS}

We thank all of the Ohio Brain Tumor Study staff and participating brain tumor patients and their families. Funding: National Institute of Health/National Cancer Institute (P30-CA043703 to Yanwen Chen and Jill S. Barnholtz-Sloan, HHSN28 $\times 273$ to Karen Devine, Andrew E. Sloan, and Jill S. Barnholtz-Sloan, HHSN261201000057C to Karen Devine, Yanwen Chen, Mark Cohen, Cathy Brewer, Cathy Schilero, Kathy Smolenski, Frances Laube, Ruth Steele, Susan Bell, Dina Aziz, E. A. Chiocca, Christopher McPherson, Ronald Warnick, Gene H. Barnett, Andrew E. Sloan, and Jill S. Barnholtz-Sloan).

\section{THE OHIO BRAIN TUMOR STUDY}

Brain tumor and neuro-oncology center at case western reserve university/university hospitals case medical center

Jill Barnholtz-Sloan, PhD, Andrew Sloan, MD, Warren Selman, MD, Stanton Gerson, MD, Nicholas Bambakidis, MD, Clifford Megerian, MD, Mark Cohen, MD, Karen Devine, RN, BSN, CNRN, Jordonna Fulop, RN, Henry Krzemien, RN, Wendi Barrett, Kristen Shimmel, Ashokkumar Patel, MD, Rajnish Gupta, Yingli Wolinsky, PhD, MBA.

\section{Rose ella burkhardt brain tumor and neuro-oncology center at the cleveland clinic}

Gene H. Barnett, MD, Manmeet Ahluwalia, MD, Michael Vogelbaum, MD, PhD, Susan Staugaitis, MD, PhD, Cathy Brewer, RN, Cathy Schilero, RN, BSN, Kathy Smolenski, RN, Barbara Denk, RN, Mary McGraw, Theresa Naska.

\section{The dardinger neuro-oncology center and the department of neurosurgery at the james cancer hospital and ohio state university medical center}

E. Antontio Chiocca, MD, PhD, Abhik Ray Chaudhury, MD, Susan Bell, CNP, BSN, MSN, Phuong Nguyen, CRC, Laurie Johnson, Kelly Senecal, Phillip Knorr, Dina Aziz.

\section{Brain tumor center at the university of cincinnati}

Ronald Warnick, MD, Christopher McPherson, MD, Ady Kendler, MD, Ruth Steele, BS, EMT-P, CCRC, Frances Laube, RN, Ashley Fehrenbach, Alison Kastl, BS, CCRC.
B. J., Rajaraman, P., Schwartzbaum, J. A., Sadetzki, S., Schlehofer, B., Tihan, T., Wiemels, J. L., Wrensch, M., Buffler, P. A., and Brain Tumor Epidemiology, C. (2008). Brain tumor epidemiology: consensus from the Brain Tumor Epidemiology Consortium. Cancer 113, 1953-1968.

CBTRUS. (2010). Statistical Report: Primary Brain Tumors in the United States, 2004-2006. Chicago: Central
Brain Tumor Registry of the United States.

de Andrade, M., Barnholtz, J. S., Amos, C. I., Adatto, P., Spencer, C., and Bondy, M. L. (2001). Segregation analysis of cancer in families of glioma patients. Genet. Epidemiol. 20, 258-270.

Hemminki, K., Forsti, A., and Ji, J. (2007). Incidence and familial risks in pituitary adenoma and associated
B., Barnholtz-Sloan, J. S., Davis, F. G., Il'Yasova, D., Kruchko, C., Mccarthy, 
tumors. Endocr. Relat. Cancer 14, 103-109.

Hemminki, K., and Li, X. (2004). Association of brain tumours with other neoplasms in families. Eur. J. Cancer 40, 253-259.

Hemminki, K., Li, X., and Collins, V. P. (2001). Parental cancer as a risk factor for brain tumors (Sweden). Cancer Causes Control 12, 195-199.

Hemminki, K., Li, X., Vaittinen, P., and Dong, C. (2000). Cancers in the first-degree relatives of children with brain tumours. Br. J. Cancer 83, 407-411.

Hill, D. A., Inskip, P. D., Shapiro, W. R., Selker, R. G., Fine, H. A., Black, P. M., and Linet, M. S. (2003). Cancer in first-degree relatives and risk of glioma in adults. Cancer Epidemiol. Biomarkers Prev. 12, 1443-1448.

Hill, D. A., Linet, M. S., Black, P. M., Fine, H. A., Selker, R. G., Shapiro, W. R., and Inskip, P. D. (2004). Meningioma and schwannoma risk in adults in relation to family history of cancer. Neuro-oncology 6, 274-280.

Kerber, R. A., and Slattery, M. L. (1997). Comparison of self-reported and database-linked family history of cancer data in a case-control study. Am. J. Epidemiol. 146, 244-248.

King, A., and Gutmann, D. H. (2000). The question of familial meningiomas and schwannomas: NF2B or not to be? Neurology 54, 4-5.

Louis, D. N., and von Deimling, A. (1995). Hereditary tumor syndromes of the nervous system: overview and rare syndromes. Brain Pathol. 5, 145-151.
Love, R. R., Evans, A. M., and Josten, D. M. (1985). The accuracy of patient reports of a family history of cancer. J. Chronic Dis. 38, 289-293.

Mai, P. L., Garceau, A. O., Graubard, B. I., Dunn, M., Mcneel, T. S., Gonsalves, L., Gail, M. H., Greene, M. H., Willis, G. B., and Wideroff, L. (2011). Confirmation of family cancer history reported in a populationbased survey. J. Natl. Cancer Inst. 103, 788-797.

Malmer, B., Feychting, M., Lonn, S., Ahlbom, A., and Henriksson, R. (2005). p53 Genotypes and risk of glioma and meningioma. Cancer Epidemiol. Biomarkers Prev. 14, 2220-2223.

Malmer, B., Henriksson, R., and Gronberg, H. (2003). Familial brain tumours-genetics or environment? A nationwide cohort study of cancer risk in spouses and first-degree relatives of brain tumour patients. Int. J. Cancer 106, 260-263.

Maxwell, M., Shih, S. D., Galanopoulos, T., Hedley-Whyte, E. T., and Cosgrove, G. R. (1998). Familial meningioma: analysis of expression of neurofibromatosis 2 protein Merlin. Report of two cases. J. Neurosurg. 88, 562-569.

McCarthy, B. J., Rankin, K. M., Aldape, K., Bondy, M. L., Brannstrom, T., Broholm, H., Feychting, M., Il'Yasova, D., Inskip, P. D., Johansen, C., Melin, B. S., Ruder, A. M., Butler, M. A., Scheurer, M. E., Schuz, J., Schwartzbaum, J. A., Wrensch, M. R., and Davis, F. G. (2011). Risk factors for oligodendroglial tumors: a pooled international study. Neuro-oncology 13, 242-250.
Ohgaki, H., and Kleihues, P. (2005). Epidemiology and etiology of gliomas. Acta Neuropathol. 109, 93-108.

Ramsey, S. D., Yoon, P., Moonesinghe, R., and Khoury, M. J. (2006). Population-based study of the prevalence of family history of cancer: implications for cancer screening and prevention. Genet. Med. 8, 571-575.

Sakas, D., Kalfakis, N., Panas, M., Vassilopoulos, D., and Carvounis, P. (1994). The risk of cancer in relatives of patients with brain neoplasm. Acta Neurochir. (Wien) 131, 226-228.

Scheurer, M. E., Etzel, C. J., Liu, M., ElZein, R., Airewele, G. E., Malmer, B., Aldape, K. D., Weinberg, J. S., Yung, W. K., and Bondy, M. L. (2007). Aggregation of cancer in first-degree relatives of patients with glioma. Cancer Epidemiol. Biomarkers Prev. 16, 2491-2495.

Wrensch, M., Lee, M., Miike, R., Newman, B., Barger, G., Davis, R., Wiencke, J., and Neuhaus, J. (1997). Familial and personal medical history of cancer and nervous system conditions among adults with glioma and controls. Am. J. Epidemiol. 145, 581-593.

Wrensch, M., Minn, Y., Chew, T., Bondy, M., and Berger, M. S. (2002). Epidemiology of primary brain tumors: current concepts and review of the literature. Neuro-oncology 4 278-299.

Wrobel, G., Roerig, P., Kokocinski, F., Neben, K., Hahn, M., Reifenberger, G., and Lichter, P. (2005). Microarray-based gene expression profiling of benign, atypical and anaplastic meningiomas identifies novel genes associated with meningioma progression. Int. J. Cancer $114,249-256$

Conflict of Interest Statement: The authors declare that the research was conducted in the absence of any commercial or financial relationships that could be construed as a potential conflict of interest.

Received: 20 December 2011; accepted: 10 February 2012; published online: 28 February 2012.

Citation: Ostrom QT, McCulloh C, Chen $Y$, Devine K, Wolinsky Y, Davitkov $P$ Robbins S, Cherukuri R, Patel A, Gupta $R$, Cohen $M$, Barrios $J V$, Brewer $C$, Schilero C, Smolenski K, McGraw M, Denk B, Naska T, Laube F, Steele $R$, Greene D, Kastl A, Bell S, Aziz D, Chiocca EA, McPherson C, Warnick R, Barnett GH, Sloan AE and BarnholtzSloan JS (2012) Family history of cancer in benign brain tumor subtypes versus gliomas. Front. Oncol. 2:19. doi: 10.3389/fonc.2012.00019

This article was submitted to Frontiers in Cancer Epidemiology and Prevention, a specialty of Frontiers in Oncology. Copyright (C) 2012 Ostrom, McCulloh, Chen, Devine, Wolinsky, Davitkov, Robbins, Cherukuri, Patel, Gupta, Cohen, Barrios, Brewer, Schilero, Smolenski, McGraw, Denk, Naska, Laube, Steele, Greene, Kastl, Bell, Aziz, Chiocca, McPherson, Warnick, Barnett, Sloan and Barnholtz-Sloan. This is an open-access article distributed under the terms of the Creative Commons Attribution Non Commercial License, which permits noncommercial use, distribution, and reproduction in other forums, provided the original authors and source are credited. 